\title{
Superconformal Cu Electrodeposition on Various Substrates
}

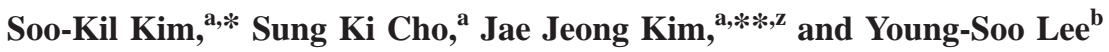 \\ ${ }^{a}$ Research Center for Energy Conversion and Storage, School of Chemical Engineering, \\ Seoul National University, San 56-1, Shillim-dong, Kwanak-gu, Seoul 151-742, Korea \\ ${ }^{b}$ Department of Environmental Engineering, Kwangwoon University, 447-1, Wolgye-dong, Nowon-gu,
} Seoul 139-701, Korea

For application to $\mathrm{Cu}$ interconnection, superconformal electrodeposition has been performed on various substrates, including physical vapor deposited (PVD) $\mathrm{Cu}$, two kinds of electroless deposited (ELD) $\mathrm{Cu}$, TiN barrier, and metallorganic chemical vapor deposited $\mathrm{Ru}$. ELD Cu with $\mathrm{HCHO}$ as the reducing agent was compatible with PVD Cu in terms of conformal characteristics and film continuity. Both PVD and ELD Cu seed layers enabled superconformal filling with distinct bumps. Superfilling was also attained on resistive substrates of TiN and Ru through Pd activation and subsequent slight seeding by electrodeposition to enhance the action of additives

(C) 2004 The Electrochemical Society. [DOI: 10.1149/1.1833687] All rights reserved.

Manuscript submitted June 28, 2004; revised manuscript received August 10, 2004. Available electronically November $29,2004$.

In the $\mathrm{Cu}$ electrodeposition process, the substrate is important to the formation of uniform and void-free $\mathrm{Cu}$ films in the damascene structure. ${ }^{1}$ There have been many investigations about the characteristics of electrodeposition on various substrate. ${ }^{2,3}$ The most widely used substrate is a physical vapor deposited (PVD) $\mathrm{Cu}$ seed layer due to its low resistivity and well-oriented crystal structure. However, poor step coverage, which is the intrinsic drawback of PVD, becomes a serious problem in nano-scale devices. On the other hand, $\mathrm{Cu}$ seed layer grown by metallorganic chemical vapor deposition (MOCVD) has superiority in step coverage. But it also has such problems as relative high resistivity and poor adhesion, ${ }^{3}$ among others. Recently, electroless deposition (ELD) has been proposed as a seed layer formation method., ${ }^{2,4}$ The merits of ELD include good step coverage, low process cost, and good uniformity on an extensive area. In particular, introduction of ELD can make an interconnection process through only wet-processes of seed layer formation with subsequent electrodeposition. In addition, there are other proposals for direct $\mathrm{Cu}$ electrodeposition on a barrier layer without a $\mathrm{Cu}$ seed layer. ${ }^{5,6}$ But the high resistivity of barrier metal does not allow the formation of a continuous $\mathrm{Cu}$ film. Kim et al. ${ }^{7}$ achieved continuous $\mathrm{Cu}$ films by using Pd activation on TiN substrates. Josell et al. ${ }^{8}$ conducted $\mathrm{Cu}$ electrodeposition on a evaporation-deposited Ru substrate.

However, the application of various substrates to damascene $\mathrm{Cu}$ electrodeposition is rather complicated because the additive chemistry is essentially involved in the electrodeposition. Generally, superconformal electrodeposition is achieved through the adsorption and catalytic effects of additives. ${ }^{9-13}$ Among them, the adsorption of an accelerator which has a mercapto group $(-\mathrm{SH})$ or disulfide $(\mathrm{S}-\mathrm{S})$ is well known on $\mathrm{Cu}$ and $\mathrm{Au}$ surface. ${ }^{4,15}$ Therefore, the existence of a $\mathrm{Cu}$ surface is essential to the function of the additives. Consequently, some variations on electrodeposition procedures according to the substrates are demanded for superconformal electrodeposition in the damascene structure.

In this study, superconformal electrodeposition was carried out on five types of substrates prepared with several deposition methods: PVD Cu, two kinds of ELD Cu, CVD TiN, and MOCVD Ru. Superconformal electrodeposition was achieved with various electrodeposition procedures according to the type of substrate used.

\section{Experimental}

Substrate fabrication.-The substrates used in the experiments were (100) oriented p-type blanket and patterned (aspect ratio of 2 and 2.5) Si wafers that were coated with CVD TiN (100 ̊)/PVD

\footnotetext{
* Electrochemical Society Student Member.

** Electrochemical Society Active Member.

${ }^{\mathrm{z}}$ E-mail: jjkimm@snu.ac.kr
}

$\operatorname{Ti}(150 \AA)$ as a diffusion barrier layer. Four types of top layer were fabricated on these wafers with optimized fabrication conditions

1. PVD $\mathrm{Cu}$ seed layer was deposited on the TiN surface by a hollow-cathode magnetron (HCM) PVD. The source was operated with a de power supply with a maximum output of $36 \mathrm{~kW}$ and the stage was cooled in the range of -50 to $-40^{\circ} \mathrm{C}$.

2. HCHO-ELD $\mathrm{Cu}$ seed (electrolessly deposited $\mathrm{Cu}$ using paraformaldehyde as the reducing agent) was fabricated with the following steps: First, the TiN surface of the substrate was cleaned by HF solution composed of $200 \mathrm{~mL}$ deionized (DI) water and $4 \mathrm{~mL}$ of $50 \% \mathrm{HF}$ by dipping the wafer for $10 \mathrm{~min}$ at room temperature to remove native Ti oxide formed on the TiN. After cleaning and rinsing with DI water, Pd activation on the pretreated TiN layer was performed at $40^{\circ} \mathrm{C}$ for $20 \mathrm{~s}$ in an activating solution, which was composed of $\mathrm{PdCl}_{2}(0.1 \mathrm{~g} / \mathrm{L}), 35 \% \mathrm{HCl}(3 \mathrm{~mL} / \mathrm{L})$, and $50 \% \mathrm{HF}(5$ $\mathrm{mL} / \mathrm{L}){ }^{2,16,17}$ Electroless deposition of $\mathrm{Cu}$ seed was performed at $50^{\circ} \mathrm{C}$ with a solution consisting of $0.005 \mathrm{M} \mathrm{CuSO}_{4} \cdot 5 \mathrm{H}_{2} \mathrm{O}, 0.01 \mathrm{M}$ ethylenediaminetetraacetic acid (EDTA), $0.015 \mathrm{M}$ paraformaldehyde ( $\mathrm{HCHO})$ as the reducing agent, and $0.05 \mathrm{M} \mathrm{KOH}$ as the $\mathrm{pH}$ adjuster. ${ }^{2,16}$

3. The same oxide cleaning step and activation step of HCHOELD $\mathrm{Cu}$ seed fabrication were done for the fabrication of Co-ELD $\mathrm{Cu}$ seed (electroless deposited $\mathrm{Cu}$ using $\mathrm{Co}(\mathrm{II})$ as a reducing agent). The electroless deposition was performed at room temperature with a deposition solution composed of $0.025 \mathrm{M} \mathrm{CuCl}_{2} \cdot 2 \mathrm{H}_{2} \mathrm{O}, 0.15 \mathrm{M}$ $\mathrm{Co}\left(\mathrm{NO}_{3}\right)_{2} \cdot 6 \mathrm{H}_{2} \mathrm{O}$ as reducing agent, $0.6 \mathrm{M}$ ethylenediamine as complexing agent, and $\mathrm{HNO}_{3}$ pre-mixed in DI water at $\mathrm{pH} 6.8 .^{2,18,19}$

4. The Ru film, one of the diffusion barrier, was deposited on TiN using the MOCVD process with a bis(ethyl- $\pi$-cyclopentadienyl) ruthenium $\left(\operatorname{Ru}(\mathrm{EtCp})_{2}\right)$ precursor. The substrate temperature for deposition was $320-360^{\circ} \mathrm{C}$. The showerhead, carrier gas (Ar) line, and reaction gas $\left(\mathrm{O}_{2}\right)$ line were heated to over $110^{\circ} \mathrm{C}$ to avoid the condensation of the precursor. The bubbler and pre-bubbler carrier line temperature was $90^{\circ} \mathrm{C}$ The flow rates for carrier gas and reaction gas were 150 and $50 \mathrm{sccm}$, respectively, and the process pressure was 3 Torr.

Surface activation prior to electrodeposition.-The PVD and two kinds of electroless $\mathrm{Cu}$ were used as seed layers for electrodeposition without any surface activation. However, Pd activation was performed on the Ru and TiN surfaces prior to the electrodeposition to enhance the initial nucleation during the electrodeposition. Activation was performed by dipping the wafer for $40 \mathrm{~s}$ in activating solutions composed of $0.28 \mathrm{mM} \mathrm{PdCl}_{2}, 36.5 \mathrm{mM} \mathrm{HCl}$, and 185.2 $\mathrm{mM} \mathrm{HF} \mathrm{HF}^{7,16,17}$ for the Ru surface at room temperature and $0.56 \mathrm{mM}$ $\mathrm{PdCl}_{2}, 36.5 \mathrm{mM} \mathrm{HCl}$, and $123.5 \mathrm{mM} \mathrm{HF}$ for the TiN surface at $40^{\circ} \mathrm{C}$. Displacement-deposited catalyst particles are known to be very effective in the formation of continuous, bright, and low resistivity $\mathrm{Cu}$ films by electrodeposition on high resistivity foreign metals. $^{7}$ 


\begin{tabular}{|c|c|c|c|c|}
\hline $\begin{array}{l}\text { Layer } \\
\text { structure }\end{array}$ & Substrate (A) & $\begin{array}{l}\text { Activation prior to } \\
\text { electrodeposition }\end{array}$ & $\begin{array}{l}\text { Electrodeposition } \\
\text { potential (vs. SCE) }\end{array}$ & Electrolyte and additives \\
\hline \multirow[t]{5}{*}{$\mathrm{A} / \mathrm{TiN} / \mathrm{Ti} / \mathrm{Si}$} & PVD Cu & None & $-250 \mathrm{mV}$ & Base electrolyte \\
\hline & HCHO-ELD Cu & None & $-250 \mathrm{mV}$ & $(\mathrm{BE})+3$ \\
\hline & $\begin{array}{l}\text { Co-ELD } \\
\mathrm{Cu}\end{array}$ & None & $-250 \mathrm{mV}$ & $\begin{array}{c}\text { additives }(\mathrm{SPS}+ \\
\mathrm{PEG}+\mathrm{NaCl})\end{array}$ \\
\hline & None & Pd activation & $\begin{array}{l}\text { Seeding: }-500 \mathrm{mV} \\
\text { Filling: }-250 \mathrm{mV}\end{array}$ & $\begin{array}{c}\text { Seeding: } \mathrm{BE}+\text { PEG } \\
\text { Filling: } \mathrm{BE}+3 \text { additives }\end{array}$ \\
\hline & $\begin{array}{l}\text { MOCVD } \\
\mathrm{Ru}\end{array}$ & Pd activation & $\begin{array}{l}\text { Seeding and filling } \\
\text { at }-200 \mathrm{mV}\end{array}$ & $\begin{array}{c}\text { Seeding: } \mathrm{BE} \\
\text { Filling: } \mathrm{BE}+3 \text { additives }\end{array}$ \\
\hline
\end{tabular}

Electrodeposition conditions and additives.-Electrodeposition on PVD and ELD seeds was performed at $-250 \mathrm{mV}$ [vs. a saturated calomel electrode (SCE)] with electrolytes composed of $1 \mathrm{M}$ $\mathrm{H}_{2} \mathrm{SO}_{4}, 0.25 \mathrm{M} \mathrm{CuSO}_{4} \cdot 5 \mathrm{H}_{2} \mathrm{O}$ and DI water (base electrolyte). Additives used in the feature filling were $50 \mu \mathrm{M}$ SPS bis(3-

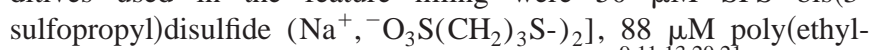
ene glycol) (PEG, Mw 3400), and $1 \mathrm{mM} \mathrm{NaCl} .^{9,11,13,20,21}$ From the authors' previous investigations, ${ }^{13}$ SPS is more effective in superconformal filling on damascene structure than MPSA 3-mercapto-1propane sulfonic acid, sodium salt, $\left.\mathrm{Na}^{+},{ }^{-} \mathrm{O}_{3} \mathrm{~S}\left(\mathrm{CH}_{2}\right)_{3} \mathrm{SH}\right]$. This is because SPS can diffuse deeply inside the trench and adsorb on the $\mathrm{Cu}$ surface without any interference from the reaction involving it as SPS is already an oxidized form. Then the adsorbed SPS undergoes reductive desorption by the applied potential to form a catalytic species (i.e., MPSA) able to reduce cupric ion to cuprous ion.

However, $\mathrm{Cu}$ electrodepostion on Pd activated Ru and TiN substrates was performed with two steps: ${ }^{7}$ electrodeposition on the Pdactivated substrate in the base electrolyte for $40-45 \mathrm{~s}$ as a seeding process, and further electrodeposition with the three-additives system stated above. For Ru substrate, seeding and filling were performed at $-200 \mathrm{mV}$. In the TiN substrate, seeding was carried out at $-500 \mathrm{mV}$ with the addition of $0.12 \mathrm{mM}$ PEG into the base electrolyte as an adhesion promoter and filling was performed at $-250 \mathrm{mV}$. Potentials were predetermined from linear sweep voltammetry. The reason for the two-step method is that the additive system has been developed for $\mathrm{Cu}$ surfaces and the reactions between the $\mathrm{Cu}$ surface and additives are quite important in superfilling. ${ }^{9,11,22}$ The equipment used in applying the potential was a PAR 263 potentiostat (EG\&G Princeton Applied Research Corporation), and a $\mathrm{Cu}$ bar was used as the anode. After electrodeposition, all samples were rinsed with DI water and dried in an $\mathrm{N}_{2}$ stream. Experimental conditions are summarized in Table I.

\section{Results and Discussion}

Figure 1 shows the cross-sectional field-emission scanning electron microscopy (FESEM) images of PVD Cu seed, HCHO-ELD Cu seed, Co-ELD Cu seed, and electrodeposited $\mathrm{Cu}$ films on each seed layer. As shown in Fig. 1a, PVD Cu seed has a uniform and conformal profile without formation of neck or seed agglomeration. Electrodeposited $\mathrm{Cu}$ film on PVD seed (Fig. 1b) exhibits a model image of superconformal filling. No voids or seams were observed either at the center or at the seed/electrodeposited $\mathrm{Cu}$ interface. In the fabrication of HCHO-ELD seed, the electroless deposition temperature was increased compared to the authors' previous method ${ }^{2}$ to reduce the surface roughness, an inveterate problem of electroless $\mathrm{Cu}$ seed, by enhancing the lateral diffusion of $\mathrm{Cu}$ adatoms. As presented in Fig. 1c, smooth, conformal, and thin $\mathrm{Cu}$ seed is evident. In the fill test, superconformal electrodeposition and formation of bumps were evidently observed (Fig. 1d). Like the case of PVD seed, the filled $\mathrm{Cu}$ had no internal defects, which shows a strong potential of the electroless $\mathrm{Cu}$ seed for $\mathrm{Cu}$ electrodeposition. However, Co-ELD seed showed a little different characteristic. Lee et al. ${ }^{23}$ have found that the Co-ELD seed underwent self-annealing phenomena resulting in large clusters. Similar results are presented in Fig. 1e. As clearly shown in the figure, the Co-ELD $\mathrm{Cu}$ seed had a conformal contour similarly to the other two seeds, while the surface was rough with a higher thickness due to the large clusters of the film. Note that the thickness control of Co-ELD Cu was difficult. In spite of the relatively undesirable seed appearance, fill-test on Co-ELD seed (Fig. 1f) showed a good profile with bumps on top. Anyway, sparse sidewall voids were noticed due to the discontinuous points of seed where the clusters met together and boundaries are formed.

Figure 2 shows the cross-sectional FESEM images of electrodeposited $\mathrm{Cu}$ on $\mathrm{Ru}$ and TiN substrates. MOCVD was found to be very effective in the formation of smooth and conformal Ru thin films compared to other methods, such as e-beam evaporation, ${ }^{8}$ as shown in the small figure in Fig. 2a. However, direct $\mathrm{Cu}$ electrodeposition on the $\mathrm{Ru}$ substrate resulted in a cluster-type deposit rather than a continuous film type in our experiments, though Josell et al. ${ }^{8}$ reported achievement of superfilling on an e-beam evaporation deposited $\mathrm{Ru}$ substrate. Therefore, two kinds of modulation of electrodeposition were introduced here to enhance the initial nucleation
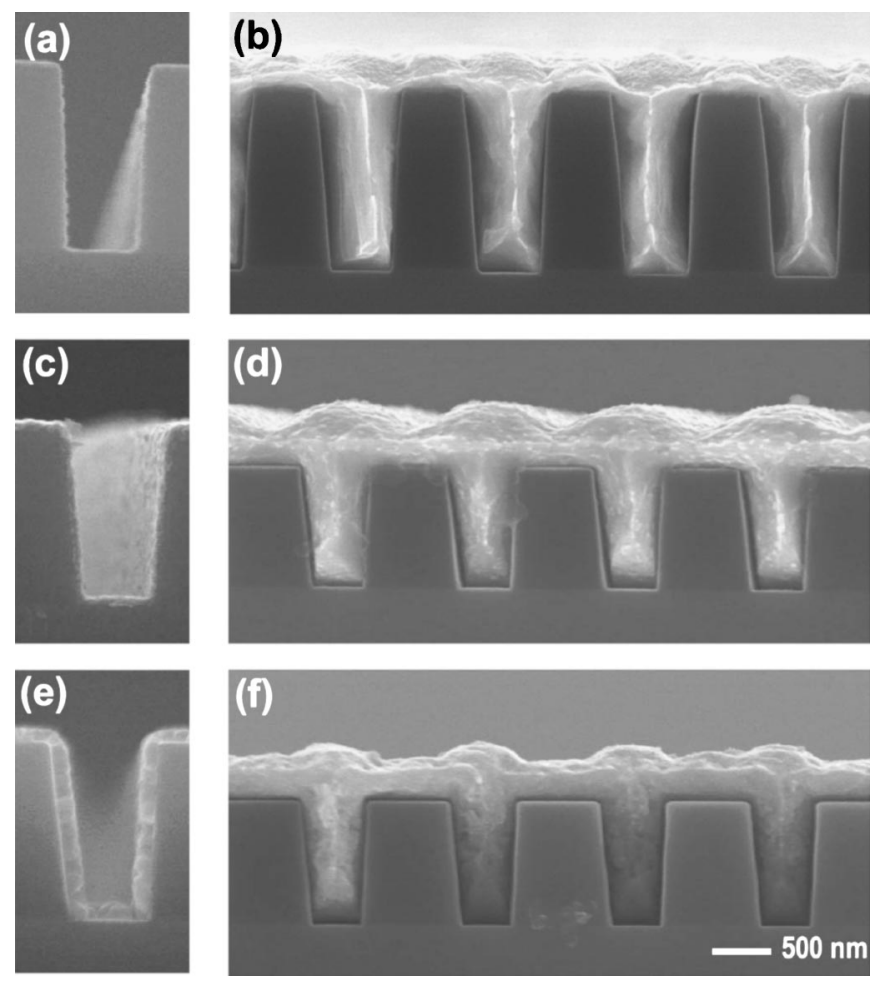

Figure 1. Cross-sectional FESEM images of (a) PVD Cu seed, (b) electrodeposited $\mathrm{Cu}$ on PVD seed, (c) HCHO-ELD Cu seed, (d) electrodeposited $\mathrm{Cu}$ on HCHO-ELD seed, (e) Co-ELD Cu seed, and (f) electrodeposited $\mathrm{Cu}$ on Co-ELD seed. Electrolyte for electrodeposition was composed of $88 \mu \mathrm{M}$ $\mathrm{PEG}, 1 \mathrm{mM} \mathrm{NaCl}$, and $50 \mu \mathrm{M}$ SPS and the electrodeposition was performed at $-250 \mathrm{mV}$ vs. SCE. 

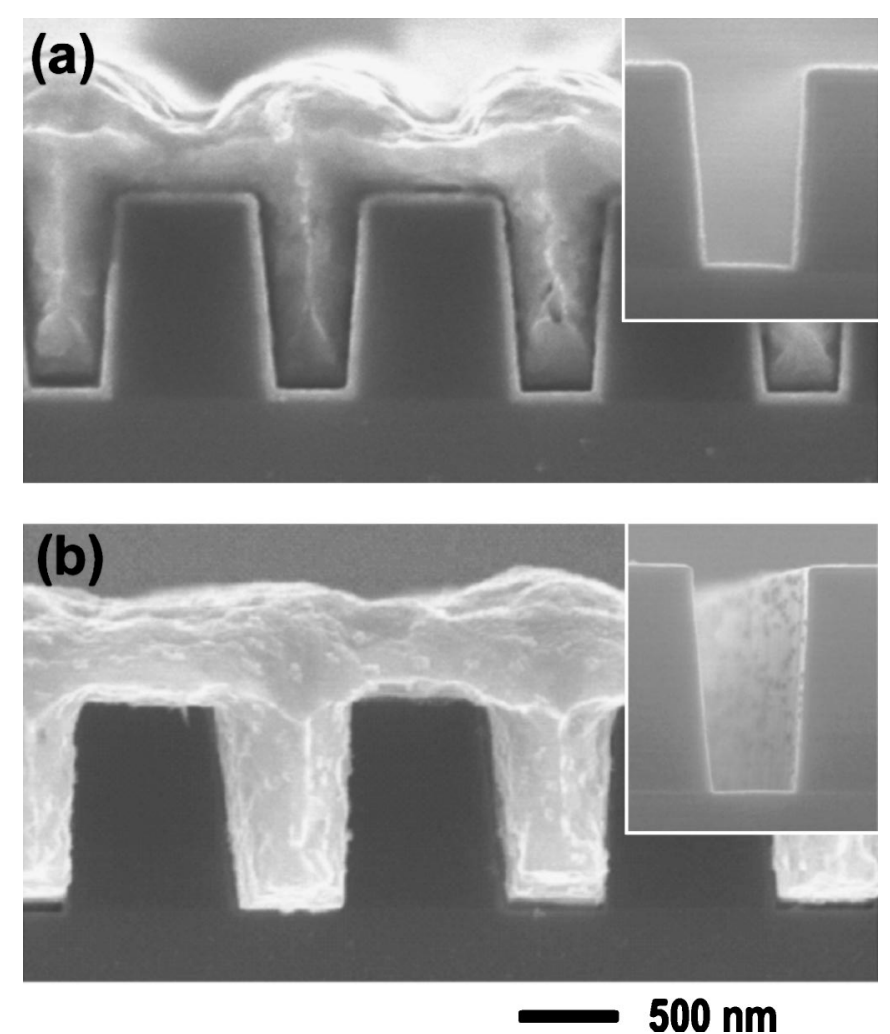

Figure 2. Cross-sectional FESEM images of electrodeposited $\mathrm{Cu}$ on (a) MOCVD Ru and (b) TiN. Small figures in (a) and (b) are MOCVD-grown Ru film and Pd-activated TiN, respectively. Prior to the electrodeposition, Pd activation for $40 \mathrm{~s}$ and subsequent seeding by electrodeposition at $-200 \mathrm{mV}$ for $45 \mathrm{~s}$ for (a) and at $-500 \mathrm{mV}$ for $40 \mathrm{~s}$ for (b) were performed. Filling with additives was carried out at $-200 \mathrm{mV}$ for (a) and at $-250 \mathrm{mV}$ for (b). Electrolyte for electrodeposition was composed of $88 \mu \mathrm{M}$ PEG, $1 \mathrm{mM} \mathrm{NaCl}$, and $50 \mu \mathrm{M}$ SPS.

density essential to continuous film formation on high resistivity substrates and to facilitate the function of additives because the mechanism was strongly based on the chemical reaction among additives, $\mathrm{Cu}$ ions, and $\mathrm{Cu}$ surface. The first change was activation of the Ru surface using Pd nano particles which would act as additional nucleation sites. The second one was $\mathrm{Cu}$ seeding on the Pd-activated $\mathrm{Ru}$ surface using electrodeposition to supply a $\mathrm{Cu}$ surface for additive because the reaction of additives with $\mathrm{Cu}$ surface, i.e., competitive adsorption between additives and reductive desoprtion of accelerator, seemed to be the most important. After introducing electrodeposited seed on the Pd-activated Ru substrate, the fill-test resulted in superconformal profile with bumps on the top surface (Fig. 2a). Similar modulations were done on the TiN substrate: Pd activation on TiN substrate (box figure in Fig. 2b) and subsequent seeding by electrodeposition. The consequent $\mathrm{Cu}$ fills (Fig. 2b) also show superfilling shape without any internal defects. These attempts to fill sub-micrometer trenches without a separate $\mathrm{Cu}$ seed fabrica- tion step allow process margin of barrier deposition or electrodeposition. However, a further optimization in activation and electrodeposition is needed to improve the filling reproducibility on these high resistivity substrates.

\section{Conclusions}

PVD $\mathrm{Cu}, \mathrm{HCHO}-\mathrm{ELD} \mathrm{Cu}, \mathrm{Co}-\mathrm{ELD} \mathrm{Cu}, \mathrm{TiN}$ barrier, and MOCVD Ru substrates were tested as substrates for damascene superconformal $\mathrm{Cu}$ electrodeposition. Despite the large clusters of CoELD $\mathrm{Cu}$, electroless deposition showed very conformal characteristics, which is important in fabrication of the seed layer. The PVD and two ELD $\mathrm{Cu}$ seed layers enabled superfilling with distinct bumps on the top. However, superfilling was attained on the resistive substrates of TiN and Ru through modification of the surface by $\mathrm{Pd}$ activation and subsequent slight seeding by electrodeposition to enhance the action of additives. These accomplishments may contribute to the diversity of approaches to the interconnection process and material.

\section{Acknowledgments}

This work was supported by KOSEF through the Research Center for Energy Conversion and Storage and by the Institute of Chemical Processes.

Seoul National University assisted in meeting the publication costs of this article.

\section{References}

1. J. Reid and S. Mayer, in Advanced Metallization Conference 1999, p. 53, M. E. Gross, T. Gessner, N. Kobayashi, and Y. Yasuda, Editors, MRS, Warrendale, PA (2000).

2. J. J. Kim, S.-K. Kim, C. H. Lee, and Y. S. Kim, J. Vac. Sci. Technol. B, 21, 33 (2003).

3. K. Weiss, S. Riedel, S. E. Schulz, M. Schwerd, H. Helneder, H. Wendt, and T. Gessner, Microelectron. Eng. 50, $433(2000)$

4. T. Hara, S. Kamijima, and Y. Shimura, Electrochem. Solid-State Lett., 6, C8 (2003).

5. G. Oskam, P. M. Vereecken, and P. C. Searson, J. Electrochem. Soc., 146, 1436 (1999).

6. A. Radisic, Y. Cao, P. Taephaisitphongse, A. C. West, and P. C. Searson, J. Electrochem. Soc., 150, C362 (2003).

7. J. J. Kim, S.-K. Kim, and Y. S. Kim, J. Electrochem. Soc., 151, C97 (2004).

8. D. Josell, D. Wheeler, C. Witt, and T. P. Moffat, Electrochem. Solid-State Lett., 6, C143 (2003).

9. T. P. Moffat, J. E. Bonevich, W. H. Huber, A. Stanishevsky, D. R. Kelly, G. R. Stafford, and D. Josell, J. Electrochem. Soc, 147, 4524 (2000).

10. D. Josell, D. Wheeler, W. H. Huber, and T. P. Moffat, Phys. Rev. Lett., 87, 016102 (2001).

11. A. C. West, S. Mayer, and J. Reid, Electrochem. Solid-State Lett., 4, C50 (2001)

12. J. J. Kim, S.-K. Kim, and Y. S. Kim, J. Electroanal. Chem., 542, 61 (2003).

13. S.-K. Kim and J. J. Kim, Electrochem. Solid-State Lett., 7, C98 (2004).

14. P. Fenter, A. Eberhardt, and P. Eisenberger, Science, 266, 1216 (1994).

15. C. D. Bain, E. B. Troughton, Y. T. Tao, J. Evall, G. M. Whitesides, and R. G. Nuzzo, J. Am. Chem. Soc., 111, 321 (1981)

16. J. J. Kim and S. H. Cha, Jpn. J. Appl. Phys., Part 1, 40, 7151 (2001).

17. P. Bindra and J. Roldan, J. Appl. Phys., 132, 258 (1985).

18. A. Vaskelis and E. Norkus, Electrochim. Acta, 44, 3667 (1999).

19. H. Nawafune, S. Nakao, S. Mizumoto, Y. Murakami, and S. Hasimoto, Hyomen Gijutsu, 50, 374 (1999).

20. D. Josell, B. Baker, C. Witt, D. Wheeler, and T. P. Moffat, J. Electrochem. Soc., 149, C637 (2002)

21. T. P. Moffat, D. Wheeler, C. Witt, and D. Josell, Electrochem. Solid-State Lett., 5, C110 (2002)

22. Y. Cao, P. Taephaisitphongse, R. Chalupa, and A. C. West, J. Electrochem. Soc., 148, C466 (2001)

23. C. H. Lee and J. J. Kim, J. Vac. Sci. Technol. B, 22, 180 (2004). 